\title{
Germinação, desenvolvimento inicial e morfoanatomia de cactáceas epifíticas
}

\author{
Germination, initial development and morpho-anatomy of epiphytic Cactaceae
}

\author{
Raquel Kremer Cury ${ }^{1}$, Aurea Maria Randi ${ }^{1,3}$ \& Marisa Santos ${ }^{2}$
}

\begin{abstract}
Resumo
Cactáceas epífitas com potencial ornamental são encontradas na Mata Atlântica brasileira. As diferenças no processo de germinação e desenvolvimento inicial, entre espécies vegetais são de interesse na produção e estabelecimento de mudas. Este estudo teve por objetivo investigar a germinação e o desenvolvimento pós-seminal in vitro, em água e ágar, e a morfoanatomia do caule de indivíduos adultos, crescendo no ambiente natural de Rhipsalis neves-armondii, Rhipsalis teres e Lepismium cruciforme, ocorrentes em Santa Catarina. Análises do crescimento e desenvolvimento foram determinadas por medidas de comprimento, massa seca, teor de clorofilas e carotenóides. Análises anatômicas do hipocótilo e caule foram obtidas por secções transversais e paradérmicas utilizando técnicas clássicas. O desenvolvimento de plântulas, em água e ágar, indicou ser indispensável a incrementação de nutrientes, pois as substâncias de reserva foram exauridas até os 60 dias de cultivo. Em ágar, as sementes de $R$. neves-armondii não germinaram. Características anatômicas do hipocótilo das plântulas, bem como do caule dos indivíduos adultos, de $R$. teres e L. cruciforme foram similares. Cutícula espessa e parênquima aquífero constatados no hipocótilo e nos caules são características xéricas, importantes para economia hídrica destas epífitas que são protegidas da irradiação solar pelo forófito, mas com limitação de disponibilidade água.

Palavras-chave: Rhipsalis, Lepismium, hipocótilo, plântulas.
\end{abstract}

\begin{abstract}
Epiphytic Cactaceae with ornamental potential are found in the Brazilian Atlantic Forest. Differences in the germination process and post-initial development among plant species are of interest in the production and establishment of seedlings. This study aimed to investigate the germination and post-seminal development in vitro, in water and agar, and the stem morpho-anatomy of adult individuals growing in the natural environment of Rhipsalis neves-armondii, R. teres and L. cruciform, occurring in Santa Catarina. Growth and development analyzes were determined by measurements of length, biomass, chlorophyll and carotenoid content. Anatomical analyzes of the hypocotyl and stem were obtained by cross - sections and parsimony using classical techniques. The development of seedlings in water and in agar, indicated that it is indispensable to increase nutrients, because the reserve substances were depleted until 60 days of cultivation. In agar, the seeds of $R$. neves-armondii did not germinate. Anatomical features of the hypocotyl of $R$. teres and $L$. cruciforme seedlings were similar. The stem of these species adult individuals also revealed a similar histological constitution. Cuticle thick and water-storage parenchyma verified in the hypocotyl of the seedlings and the stems of adult plants are xeric characteristics, important for water economy of these epiphytes that are protected of the solar irradiation by the phorophyte, but with limitation of water availability. Key words: Rhipsalis, Lepismium, hypocotyl, seedlings.
\end{abstract}

\section{Introdução}

Cactos estão presentes em uma variedade de hábitats com uma ampla gama de formas (Anderson 2001). As Cactaceae adaptadas ao epifitismo são encontradas na Mata Atlântica brasileira e destacam-se especialmente na região litoral, onde essas espécies são frequentes, como é o caso dos gêneros Lepismium Pfeiff. e Rhipsalis Gaertn. (Calvente 2010; Zappi et al. 2011). Os cactos apresentam considerável importância na floresta tropical, especialmente atraindo dispersores e auxiliando na manutenção da biodiversidade, e

\footnotetext{
${ }^{1}$ Universidade Federal de Santa Catarina (UFSC), Centro de Ciências Biológicas, Depto. Botânica, Campus Universitário, Florianópolis, 88040-900, SC, Brasil. raqkr@hptmail.com

${ }^{2}$ Universidade Federal de Santa Catarina (UFSC), Centro de Ciências Biológicas, Depto. Botânica, Campus Universitário, Florianópolis, 88040-900, SC, Brasil. marisa.santos@ufsc.br

${ }^{3}$ Autor para correspondência: amrandi@ccb.ufsc.br.
} 
possuem valor comercial como plantas ornamentais. O comércio ornamental com Cactaceae epifíticas é intenso (Barthlott \& Hunt 2000). Geralmente, a coleta predatória e indiscriminada para o comércio de colecionadores, e também a degradação do ambiente através das atividades humanas, têm colocado muitas populações de cactos em perigo (Anderson 2001; Nobel 2002). Entretanto, a maioria dos estudos com espécies de Cactaceae não abordam aspectos relacionados com germinação e desenvolvimento, sendo ainda mais escassas pesquisas com espécies epifíticas.

A obtenção de plântulas de Cactáceas pode ser feita por germinação de sementes, por propagação vegetativa e pelo cultivo de tecidos in vitro (RojasAréchiga \& Vázquez-Yane 2000). A germinação através do cultivo in vitro é considerada uma boa alternativa para a produção de mudas, tanto para os viveiristas e pecuaristas, quanto para projetos que visem à conservação das espécies de Cactaceae epífitas (Rojas-Aréchiga \& Vázquez-Yane 2000; Zaidan \& Barbedo 2004). Esta técnica é utilizada sob condições controladas, para que o estabelecimento de determinada espécie, tenha a composição ideal do meio de cultura e as condições ambientais preliminarmente requeridos como temperatura, substrato, luminosidade e disponibilidade de água (Godínez-Álvarez et al. 2003; Hoppe et al. 2004). No entanto, os estudos conhecidos com germinação in vitro de Cactaceae epífitas, tem obtido baixo rendimento na produção de plântulas, provavelmente pelo pouco conhecimento sobre os requisitos germinativos de sementes de cactos e sobre a sua viabilidade e longevidade (Guillén et al. 2009; Quiala et al. 2009).

Sendo assim, o presente estudo teve como objetivo investigar a germinação e o desenvolvimento pós-seminal in vitro, em água e em ágar, e caracterizar a morfoanatomia do caule de indivíduos adultos crescendo no ambiente natural, de três espécies de Cactaceae epifíticas, Rhipsalis neves-armondii K. Schum., Rhipsalis teres Steud e Lepismium cruciforme (Vell.) Miq. A caracterização morfoanatômica das plântulas nas fases iniciais, bem como da estrutura caulinar de indivíduos adultos, pode corroborar com o entendimento da composição histológica associada as condições adaptativas destas espécies epifíticas. Como decorrência, estes estudos poderão subsidiar procedimentos de produção e estabelecimento de mudas para suprir mercado econômico com espécies ornamentais e, com isto, minimizar a exploração predatória nos ambientes naturais.

\section{Material e Métodos}

Material botânico - Frutos e caules de Rhipsalis neves-armondii (Fig. 1a), R. teres. (Fig. 1b) e $L$. cruciforme ((Fig. 1c) foram coletados na Floresta Atlântica, na região litorânea dos municípios de Itajaí (26 54'28'S e 4839'43"O) e de Florianópolis ( $27^{\circ} 35^{\prime} 49^{\prime \prime}$ 'S e $48^{\circ} 32^{\prime} 58^{\prime \prime}$ ), no estado de Santa Catarina. As sementes usadas no experimento foram extraídas dos frutos e secas em bancada de laboratório, em temperatura ambiente, durante 72 horas e mantidas por dois anos, sob refrigeração à 4 $\pm 2{ }^{\circ} \mathrm{C}$. As exsicatas foram preparadas, e depositadas no Herbário Flor - UFSC sob os respectivos números: $R$. neves-armondii 53.126, 53.127, 53.128, $53.130,53.131,53.132$ e $53.134 ; R$. teres 53.129 e 53.133; e L. cruciforme 53.135. A identificação das exsicatas foi realizada pela professora Dra Alice de Moraes Calvente Versieux da UFRN.

Análise morfológica das sementes - Foram selecionadas aleatoriamente cinco sementes por espécie de $R$. neves-armondii, $R$. teres e L. cruciforme e classificadas, conforme Barthlott \& Hunt (2000), de acordo o comprimento: extremamente grande (4 $4,8 \mathrm{~mm})$; muito grande (3-3,9 mm); grande (2-2,9 $\mathrm{mm})$; média $(1,2-1,9 \mathrm{~mm})$; pequena $(0,9-1,1 \mathrm{~mm})$ e muito pequena $(0,3-0,8 \mathrm{~mm})$. As dimensões das sementes, comprimento e largura, foram medidas com paquímetro universal Kingtools 500150 (São Paulo, Brasil) e a massa fresca foi determinada em balança eletrônica de precisão Gehaka BG 200 (São Paulo, Brasil). Imagens das sementes foram obtidas em microscópio estereoscópico Leica EZ4D (Wetzlar, Alemanha) equipado com câmara digital Sony DSCW80 (Shenzhen, China).

Viabilidade das sementes - Foram utilizadas sementes de 10 indivíduos de cactáceas epífitas, sendo cinco sementes por indivíduo. Os indivíduos, localizados em diferentes pontos da área de coleta, foram numerados: 1 e $2-R$. neves-armondii; 3 a 9 - R. teres; e 10 - L. cruciforme.

Os tegumentos das sementes foram removidos, expondo o embrião para facilitar absorção. Os embriões foram submetidos ao Teste de Tetrazólio, sendo completamente imersos em solução de cloreto de 2,3,5- trifeniltetrazólio (TTC) Merk $^{\circledR}$, a 1\% e mantidos no escuro, em temperatura ambiente (aproximadamente $20^{\circ} \mathrm{C}$ ). A viabilidade foi avaliada em três, seis e 12 horas após imersão, sendo as sementes classificadas conforme as regras de análise de sementes (Brasil 2009): I) sementes viáveis - embriões com coloração vermelha ou rosada, uniformemente ou com grandes áreas coradas; ou 
II) sementes não viáveis - embriões sem coloração ou com a maior parte da superfície não corada.

Germinação das sementes - As sementes foram superficialmente esterilizadas em solução de hipoclorito de sódio a $1 \%$ durante 1 minuto, lavadas três vezes em água destilada, esterilizadas em autoclave, e filtradas em peneira com $3 \mathrm{~cm}$ de diâmetro. Após assepsia, as sementes de Rhipsalis neves-armondii, $R$. teres, $L$. cruciforme, foram inoculadas em frasco de vidro com capacidade de $100 \mathrm{ml}$, contendo $15 \mathrm{ml}$ de Agar com $1 \mathrm{ml}$ de água destilada sobreposto. Os fracos foram fechados com tampa transparente de polipropileno e as bordas protegidas com filme transparente de PVC (Rolopac ${ }^{\circledR}$ ). A vidraria e os meios de cultivo foram previamente esterilizados em autoclave, por 20 minutos, a $120^{\circ} \mathrm{C}$. Todos os procedimentos de assepsia e de inoculação das sementes foram realizados em Câmara de Fluxo Laminar.

Foram inoculadas 80 sementes de cada espécie para este experimento, sendo uma semente por frasco. Os frascos com as sementes foram mantidos em sala de crescimento com temperatura de $25 \pm 2{ }^{\circ} \mathrm{C}$, umidade relativa do ar de aproximadamente $60 \%$, fotoperíodo de $16 / 8$ horas luz/escuro em sala de vegetação e iluminação obtida por lâmpadas fluorescentes brancas com densidade de fluxo de fótons de $30 \mu \mathrm{mol} \mathrm{m} \mathrm{m}^{-2}$. As avaliações de germinação foram realizadas 15, 30 e 60 dias após a inoculação. Foi considerada germinada aquela semente que apresentava a protrusão da raiz. O delineamento experimental foi inteiramente casualizado. Os dados obtidos do experimento foi submetido à análise de variância e as médias foram comparadas pelo teste de Tukey $(\mathrm{p}<0,05)$. O programa utilizado para as análises de variância foi o VARPC, desenvolvido pelo professor Dr. Ladaslav Sodek, do Departamento de Fisiologia Vegetal do Instituto do Biologia, da Universidade Estadual de Campinas.

Crescimento e desenvolvimento das plântulas - Para estas análises foram selecionadas aleatoriamente 140 sementes por espécie, de $R$. neves-armondii, $R$. teres e L. cruciforme, e inoculadas sobre papel filtro umedecido com $2 \mathrm{ml}$ de água destilada esterilizada, em quatro placas de petri, sendo 35 sementes por placa. O delineamento experimental foi inteiramente casualizado com 4 repetições, sendo considerando cada placa de petri uma repetição. Foram utilizadas plântulas obtidas por germinação em água, conforme procedimento descrito acima. O número amostral das análises de desenvolvimento e crescimento foram de 10

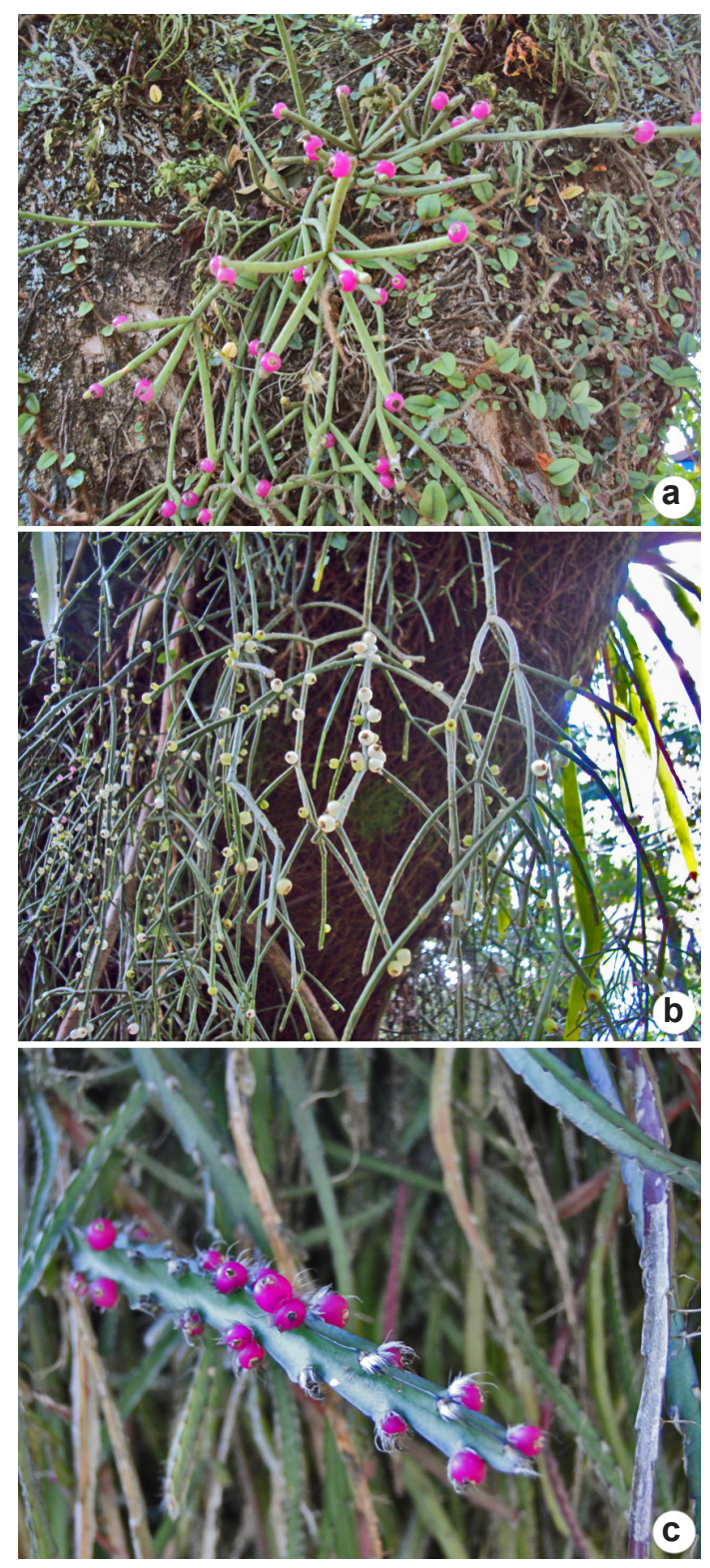

Figura 1 - Indivíduos adultos com frutos em ambiente natural - a. Rhipsalis neves-armondii K. Schum.; b. Rhipsalis teres Steud.; c. Lepismium cruciforme (Vell.) Miq.

Figure 1 - Adult individuals with fruits in natural environment - a. Rhipsalis neves-armondii K. Schum.; b. Rhipsalis teres Steud.; c. Lepismium cruciforme (Vell.) Miq.

plântulas de cada espécie. A vidraria e os meios de cultivo foram previamente esterilizados em autoclave, por 20 minutos, a $120^{\circ} \mathrm{C}$. Todos os procedimentos de assepsia e de inoculação das sementes foram realizados em Câmara de Fluxo Laminar. 
As análises de crescimento foram feitas aos 60 dias após a semeadura. Foram considerados os comprimentos da parte aérea (CPA) e de raiz primária (CR), o número de raízes (NR), a massa fresca total (MFT), a massa fresca da parte aérea (MFP) e a massa fresca das raízes (MFR). O comprimento da parte aérea foi obtido pela medida a partir do colo da plântula até o ápice do cotilédone. O comprimento do sistema radicular foi obtido considerando o ápice da maior raiz até o colo. Ambas as medidas foram feitas com auxilio de um paquímetro universal Kingtools 500150 (São Paulo, Brasil). A massa fresca da plântula foi obtida em balança eletrônica de precisão Gehaka BG 200 (São Paulo, Brasil). Os dados foram submetidos à análise de variância e as médias foram comparadas entre as espécies pelo teste de Tukey $(\mathrm{p}<0,05)$. O programa utilizado para as análises de variância foi o VARPC, desenvolvido pelo professor Dr. Ladaslav Sodek, do Departamento de Fisiologia Vegetal do Instituto do Biologia, da Universidade Estadual de Campinas.

As análises de desenvolvimento das plantas foram feitas aos 30 e 60 dias após a semeadura, realizada pela determinação do teor de clorofilas e carotenóides em plântulas frescas, através do método colorimétrico descrito por Lichtenthaler (1987). Foram utilizadas três amostras de 10 plantas de cada espécie, aos 60 dias após a semeadura. A extração, em acetona $100 \%$, foi realizada em graal e pistilo. Em seguida o extrato foi filtrado em papel de filtro, em balão volumétrico $(25 \mathrm{~mL})$, devidamente revestido por papel alumínio. Posteriormente, o graal e filtro foram lavados com acetona $100 \%$ e o volume do balão foi completado até $25 \mathrm{~mL}$. Os teores de clorofilas e caroteneoides foram lidos em espectrofotômetro, usando três alíquotas de cada amostra $(n=9)$. Foi determinada a absorvância nos comprimentos de onda de $470 \mathrm{~nm}$ para a leitura de carotenóides e 645 e $662 \mathrm{~nm}$ para leitura das clorofilas. As clorofilas e carotenóides foram calculados a partir das seguintes equações: $\mathrm{Ca}=$ $11,24 \mathrm{~A}_{662}-2,04 \mathrm{~A}_{645} ; \mathrm{Cb}=20,13 \mathrm{~A}_{645}-4,19 \mathrm{~A}_{662} ; \mathrm{C}$ total $=7,05 \mathrm{~A}_{662}+18,09 \mathrm{~A}_{645} ;$ Carotenóides $=[(1000$ $\left.\left.\mathrm{A}_{470}-1,9 \mathrm{Ca}-63,14 \mathrm{Cb}\right) / 214\right]$.

Análise morfoanatômica das plântulas Foram realizados estudos morfoanatômicos apenas nas plântulas de Rhipsalis teres e L. cruciforme, germinadas e desenvolvidas em água e em Agar, já que $R$. neves-armondii não germinou neste tratamento, como será apresentado nos resultados e discussão deste trabalho. Foram utilizadas amostras de parte aérea (hipocótilo) de 5 plântulas e o primeiro artículo, sentido ápice-base, de caules de plantas adultas crescidas na natureza de cada espécie.
Amostras foram fixadas em glutaraldeído 2,5\% em tampão fosfato de sódio $0,1 \mathrm{M}$, em pH 7,2, por 3 horas, lavadas na mesma solução tampão e desidratadas em série etílica gradual. Para estudos em Microscopia Óptica (MO), amostras foram infiltradas em hidroxietilmetacrilato (Jung's historesin-Leica ${ }^{\circledR}$ ), conforme instruções do fabricante. Secções transversais de $5 \mu \mathrm{m}$ de espessura foram feitas em micrótomo de rotação Leica -RM 2125 RT (Nussoch, Alemanha) e coradas com azul de toluidina (O'Brien et al. 1964). As análises e registro de imagens foram obtidas em Microscópio Óptico DM 2500 (Leica, Wetzlar, Alemanha), equipado com câmera DFC 295 (Heerbrugg, Alemanha) e software (Leica Application Suite 3.7.0, Suíça). Para análises em Microscópico Eletrônico de Varredura (MEV) amostras desidratadas foram submetidas ao ponto crítico de $\mathrm{CO}_{2}$ Leica EM CDP 300 (Wetzlar, Alemanha), conforme procedimento de Horridge \& Tamm (1969) e colocadas sobre suportes de alumínio, com auxílio de fita de carbono de dupla face, e cobertas com $20 \mathrm{~nm}$ de ouro, em metalizador Leica modelo EM SCD 500 (Wetzlar, Alemanha). A análise e documentação foram efetivadas em Microscópio Eletrônico de Varredura JEOL JSM6390 LV (Tokio, Japão) no Laboratório Central de Microscopia (LCME) da UFSC.

\section{Resultados e Discussão}

As sementes das espécies estudadas revelaramse pequenas e, seguindo a classificação Barthlott \& Hunt (2000), com distintas formas: ovóide, em Rhipsalis neves-armondii (Fig. 2a) e R. teres (Fig. 2b), e cônica, em L. cruciforme (Fig. 2c). Nas três espécies, a testa mostrou-se rígida, de cor marromescura a preta, com aspecto liso e brilhante. $\mathrm{Na}$ região mais angulada da semente, localiza-se a zona hilo micropilar (Fig. 2a-c). Com base nas médias das dimensões (comprimento e largura) e massa fresca total (MF), constatou-se que as sementes de L. cruciforme se apresentaram com maior tamanho e maior massa fresca do que as sementes de $R$. neves-armondii e $R$. teres, estas semelhantes entre si (Tab. 1). As sementes destas três espécies foram classificadas como pequenas conforme Barthlott $\&$ Hunt (2000). A morfologia das sementes de Cactaceae, como coloração do tegumento, forma e tamanho, possibilitam a diferenciação de espécies e gêneros (Barthlott \& Hunt 2000; Arias \& Terrazas 2004; Loza-Cornejo et al. 2008). A caracterização morfológica de sementes de $L$. cruciforme e $R$. neves-armondii e $R$. teres apresentou a zona hilo 

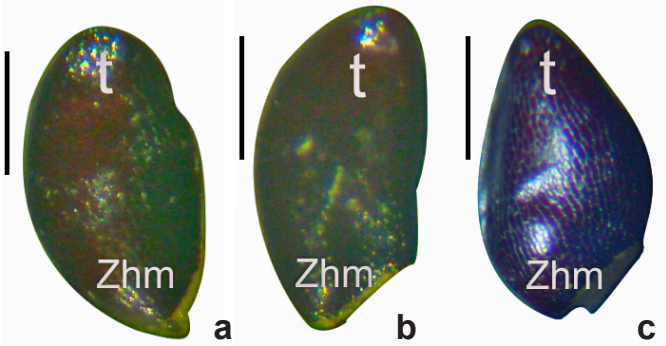

Figura 2 - Aspecto geral das sementes - a. Rhipsalis neves-armondii K. Schum.; b. Rhipsalis teres Steud.; c. Lepismium cruciforme (Vell.) Miq. Legenda: $\mathrm{t}$ - testa, $\mathrm{Znm}$ - zona hilo-micropilar. Barras: 0,5 mm.

Figure 2 - General appearance of a. Rhipsalis neves-armondii $\mathrm{K}$. Schum.; b. R. teres Steud.; c. Lepismium cruciforme (Vell.) Miq. Caption: $\mathrm{t}$ - test, Znm - wire-micropillary zone. Bars: 0,5 mm.

micropilar unida, como ocorre normalmente em gêneros de Cactoideae (Barthlott \& Hunt 1993). Os gêneros Rhipsalis e Lepismium apresentam sementes com tamanho reduzido, com forma bastante peculiar, úteis para identificação de gênero e espécie (Cavalcante et al. 2013).

O teste de tetrazólio (TTC), usado para avaliar a viabilidade das sementes, demonstrou que todas as sementes armazenadas estavam viáveis após dois anos de armazenamento sob refrigeração. Após três horas de exposição dos embriões ao TTC observou-se coloração rosada em 100\% das amostras nas três espécies. Entretanto, a coloração vermelha uniforme só foi obtida após 12 horas (Fig. 3). Conforme Brasil (2009), o resultado indicou que as sementes eram viáveis, capazes de produzir plântulas normais sob condições favoráveis, depois de superada a dormência, ou após a desinfecção das mesmas, quando necessária. A coloração uniforme, menciona ainda o autor, que além de indicar que a semente é viável, descarta a possibilidade de haver porções variáveis de tecido necrosado que poderiam ser encontradas quando embriões apresentam regiões parcialmente coloridos.
As sementes de muitas espécies de cactos são predominantemente ortodoxas, podendo manter altas taxas de germinação após longos períodos de armazenamento (Barbedo et al. 2002). Algumas espécies podem aumentar a taxa de germinação, quando armazenadas em condições adequadas, mantendo-se viáveis por períodos de até 24 meses. Após o armazenamento por longo período, as sementes de cactos ainda são capazes de germinar e produzir plantas normais. Entretanto, o acondicionamento das sementes em ambientes com variações de temperatura ou a presença de componentes químicos, durante o processo de embebição, podem interferir na porcentagem de germinação (Rojas-Aréchiga \& Vázquez-Yanes 2000; Flores et al. 2008; Brasil 2009). As sementes das espécies estudadas neste trabalho mantiveramse viáveis durante dois anos de armazenamento sob refrigeração e produziram plântulas.

A germinação de sementes das espécies de Cactaceae epifíticas armazenadas durante dois anos mostrou diferenças entre as espécies, tanto na velocidade quanto na porcentagem de germinação (Tab. 2). Rhipsalis teres apresentou $57 \%$ de sementes germinadas, após 15 dias, enquanto em $R$. neves-armondii e L. cruciforme não apresentaram germinação das sementes. Somente aos 30 dias, $R$. neves-armondii e L. cruciforme atingiram 50\% e $40 \%$ de germinação, respectivamente. Rhipsalis teres, após 30 dias, já havia atingido 71,5\%. Após 60 dias de cultivo, a germinação das sementes de $R$. teres atingiu $100 \%$ e L . cruciforme chegou a $80 \%$. Rhipsalis neves-armondii estabilizou a germinação aos 30 dias, mantendo apenas $40 \%$ das sementes germinadas, pois algumas plântulas produzidas na germinação morreram.

A germinação de $R$. neves-armondii, $R$. teres e L. cruciforme, foi do tipo fanerocotiledonar. Nos estudos de Bregman \& Bouman (1983), foi caracterizado a germinação com hipocótilo de reserva, pois a nutrição inicial da plântula suprida

Tabela 1 - Dimensões e massa fresca (MF) de sementes de Cactaceae epifíticas.

Table 1 - Dimensions and fresh mass (MF) of epiphytic Cactaceae seeds.

\begin{tabular}{lccc}
\hline \multicolumn{1}{c}{ Espécie } & Comprimento $(\mathbf{m m})$ & Largura $(\mathbf{m m})$ & Massa fresca $(\mathbf{m g})$ \\
\hline Rhipsalis neves-amondii & $0,95 \pm 0,10 \mathrm{~B}$ & $0,41 \pm 0,05 \mathrm{~B}$ & $0,23 \pm 0,02 \mathrm{~B}$ \\
Rhipsalis teres & $0,96 \pm 0,05 \mathrm{~B}$ & $0,47 \pm 0,05 \mathrm{~B}$ & $0,23 \pm 0,02 \mathrm{~B}$ \\
Lepismium cruciforme & $1,07 \pm 0,63 \mathrm{~A}$ & $0,53 \pm 0,13 \mathrm{~A}$ & $0,26 \pm 0,02 \mathrm{~A}$ \\
\hline
\end{tabular}

Médias seguidas da mesma letra na coluna não diferem entre si pelo teste de Tukey a $5 \% . n=10$. 

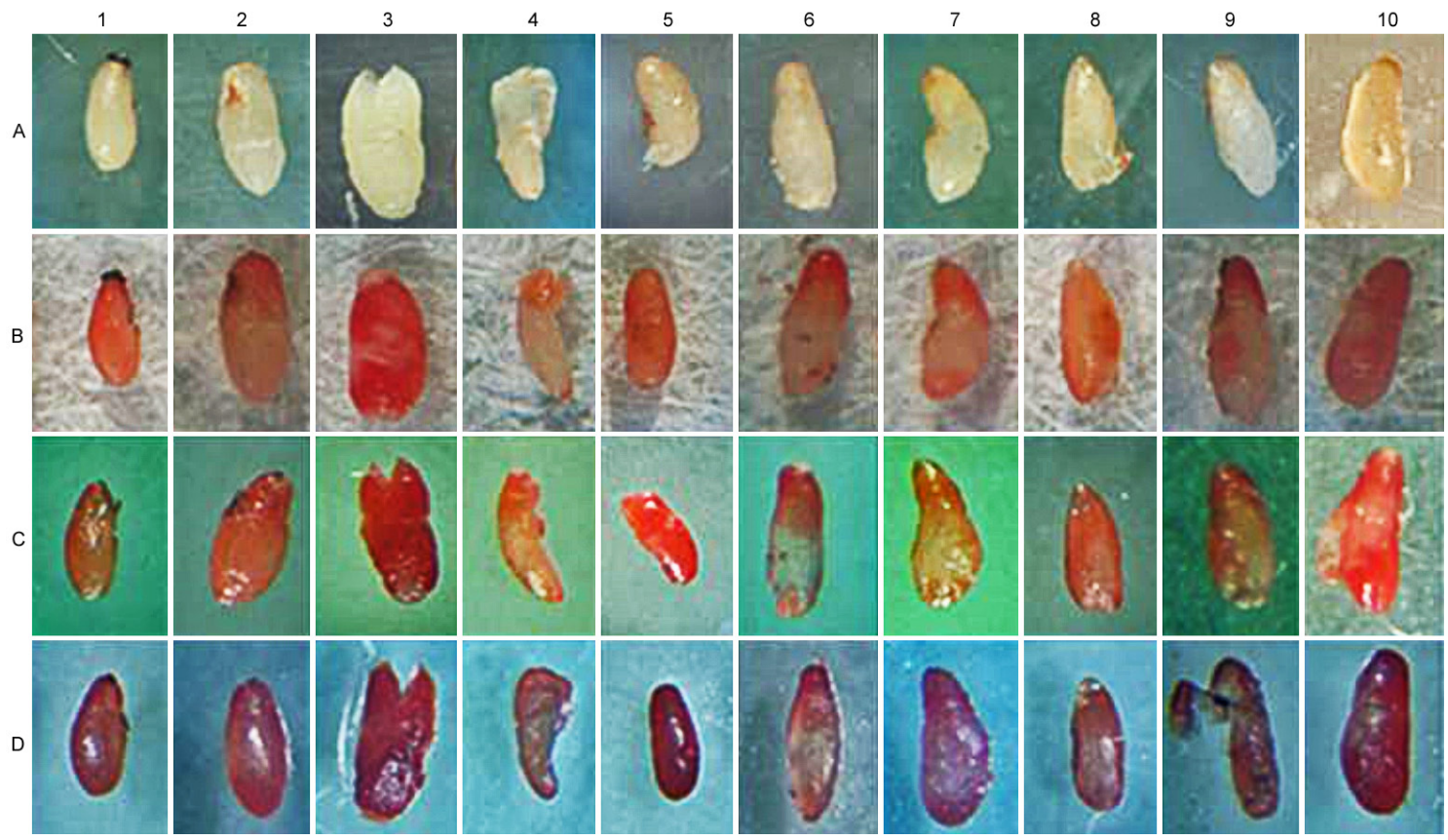

Figura 3 - Teste de viabilidade dos embriões zigóticos, após imersão em solução de cloreto 2,3,5 trifenil tetrazólio (TTC) a 1\%: antes da imersão (a) e 3h (b), $6 \mathrm{~h}$ (c) e $12 \mathrm{~h}$ (d) após a imersão nos indivíduos de Rhipsalis neves-armondii (1-2), Rhipsalis teres (3-9) e Lepismium Cruciforme (10). Legenda: t - testa, Znm - zona hilo-micropilar.

Figure 3 - Zygotic embryo viability test after immersion in chloride solution 2,3,5 triphenyl tetrazolium chloride $1 \%$ (TTC): before immersion (a) and $3 \mathrm{~h}(\mathrm{~b}), 6 \mathrm{~h}(\mathrm{c})$ and $12 \mathrm{~h}(\mathrm{~d})$ after immersion in Rhipsalis neves-armondii (1-2), Rhipsalis teres (3-9) and Lepismium Cruciforme (10) genotypes. Caption: $\mathrm{t}$ - test, Znm - hilum-micropillary area.

Tabela 2 - Percentagem de germinação de sementes cultivadas em água, mantidas em câmara de crescimento (temperatura de $25 \pm 2{ }^{\circ} \mathrm{C}$, umidade do ar aproximadamente $60 \%$, fotoperíodo de $16 / 8$ horas luz/escuro, luz branca fria fluorescente e intensidade de $\left.30 \mu \mathrm{mol} \cdot \mathrm{m}^{-2} \cdot \mathrm{s}^{-1}\right) . \mathrm{n}=5$.

Table 2 - Percentage of germination of seeds grown in water, maintained in a growth chamber (temperature of $25 \pm 2{ }^{\circ} \mathrm{C}$, air humidity

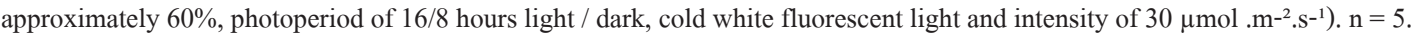

\begin{tabular}{lccc}
\hline \multicolumn{1}{c}{ Espécies } & \multicolumn{3}{c}{ Tempo de Germinação (\% Germinação) } \\
& 15 dias & 30 dias & 60 dias \\
\hline Rhipsalis neves-armondii & 0 & 50 & 40 \\
Rhipsalis teres & 57 & 71,5 & 100 \\
Lepismium cruciforme & 0 & 40 & 80 \\
\hline
\end{tabular}

A percentagem de germinação é cumulativa na linha. $\mathrm{n}=10$.

pelo hipocótilo, uma vez que os cotilédones se apresentam rudimentares, como é característico de outras espécies de cactos.

A análise do crescimento das plântulas de $R$. neves-armondii, $R$. teres e L. cruciforme a partir das sementes germinadas em água mostrou diferenças entre as espécies (Tab. 3). $\mathrm{O}$ comprimento da parte aérea (CPA) e a massa fresca das raízes (MFR) nas três espécies estudadas apresentaram-se distintas entre si. Rhipsalis neves- armondii apresentou maior comprimento da parte aérea e mais massa fresca de raízes do que em $R$. teres e L. cruciforme. Os valores de massa fresca total (MFT) e da parte aérea (MFPA) também foram maiores em $R$. neves-armondii.

Os resultados obtidos para massa fresca estão relacionados com a composição de nutrientes do meio de cultura, e é afetado pela composição gasosa da atmosfera no interior do recipiente de cultivo in vitro e pela intensidade de luz (Barber \& Anderson 
Tabela 3 - Análises do crescimento e desenvolvimento de plântulas cultivadas em água de espécies de Cactaceae epifíticas 60 dias após as sementes serem colocadas para germinar, em câmara de crescimento com temperatura de $25 \pm$ $2{ }^{\circ} \mathrm{C}$, umidade do ar de $\cong 60 \%$, com fotoperíodo de 16/8 horas luz/escuro, luz branca fria fluorescente, com intensidade de $30 \mu \mathrm{mol} \cdot \mathrm{m}^{-2} \cdot \mathrm{s}^{-1}$ : medidas do Comprimento da Parte Área (CPA), Comprimento da Raiz (CR) e Número de Raizes (NR); produção de biomassa em massa fresca total (MFT), massa fresca da parte aérea (MFPA) e massa fresca das raízes (mg) (MFR); Concentração de Clorofila a, b e total e Carotenóides ( $\mu$ g do pigmento/mg de Massa Fresca). Table 3 - Analysis of the growth and development of seedlings grown in water of epiphytic Cactaceae species 60 days after the seeds were germinatedIn a growth chamber with a temperature of $25 \pm 2{ }^{\circ} \mathrm{C}$, air humidity of $\cong 60 \%$, with photoperiod of $16 / 8$ hours light / dark, cold white fluorescent light, with intensity of $30 \mu \mathrm{mol} . \mathrm{m}^{-2} \cdot \mathrm{s}^{-1}$ : Area Part Length (CPA) measurements, Root Length (CR) and Number of Roots (NR); production of biomass in total fresh mass (MFT), fresh shoot mass (MFPA) and fresh root mass (mg) (MFR); concentration of Chlorophyll a, b and total and Carotenoids ( $\mu \mathrm{g}$ of pigment / mg of Fresh Pasta).

Parâmetros avaliados

\section{Espécies}

\begin{tabular}{lccc} 
& Rhipsalis neves-armondii & Rhipsalis teres & Lepismium cruciforme \\
\hline CPA $(\mathrm{mm})$ & $3,60 \pm 094 \mathrm{~A}$ & $3,05 \pm 0,37 \mathrm{AB}$ & $2,70 \pm 0,26 \mathrm{~B}$ \\
$\mathrm{NR}$ & $1,50 \pm 0,71 \mathrm{~A}$ & $1,00 \pm 0,00 \mathrm{~A}$ & $1,40 \pm 0,52 \mathrm{~A}$ \\
$\mathrm{CR}(\mathrm{mm})$ & $7,20 \pm 2,26 \mathrm{~A}$ & $6,80 \pm 4,37 \mathrm{~A}$ & $6,65 \pm 3,65 \mathrm{~A}$ \\
MFT $(\mathrm{mg})$ & $5,51 \pm 1,37 \mathrm{~A}$ & $2,95 \pm 1,33 \mathrm{~B}$ & $3,88 \pm 1,59 \mathrm{~B}$ \\
MFPA $(\mathrm{mg})$ & $5,12 \pm 1,33 \mathrm{~A}$ & $2,64 \pm 0,32 \mathrm{~B}$ & $3,45 \pm 0,33 \mathrm{~B}$ \\
MFR $(\mathrm{mg})$ & $0,43 \pm 0,14 \mathrm{~A}$ & $0,31 \pm 0,20 \mathrm{AB}$ & $0,20 \pm 0,12 \mathrm{~B}$ \\
Clorofila a $(\mu \mathrm{g} \mathrm{Ca} / \mathrm{mg} \mathrm{MF})$ & $0,11 \pm 0,03 \mathrm{C}$ & $0,48 \pm 0,02 \mathrm{~A}$ & $0,32 \pm 0,03 \mathrm{~B}$ \\
Clorofila b $(\mu \mathrm{g} \mathrm{Cb} / \mathrm{mg} \mathrm{MF})$ & $0,23 \pm 0,02 \mathrm{C}$ & $0,90 \pm 0,01 \mathrm{~A}$ & $0,62 \pm 0,01 \mathrm{~B}$ \\
Clorofila total $(\mu \mathrm{g} \mathrm{Ct} / \mathrm{mg} \mathrm{MF})$ & $0,34 \pm 0,02 \mathrm{C}$ & $1,39 \pm 0,02 \mathrm{~A}$ & $0,94 \pm 0,01 \mathrm{~B}$ \\
Carotenóides $(\mu \mathrm{g} \mathrm{Carot.} / \mathrm{mg} \mathrm{MF})$ & $0,01 \pm 0,00 \mathrm{C}$ & $0,06 \pm 0,02 \mathrm{~A}$ & $0,03 \pm 0,01 \mathrm{~B}$ \\
\hline
\end{tabular}

Médias seguidas da mesma letra maiúscula na linha não diferem entre si pelo teste de Tukey a $5 \% . \mathrm{n}=10$.

1992; Zobayed et al. 2000; Ibaraki \& Nozaki 2005). O crescimento, ou obtenção de massa fresca é influenciado pela disponibilidade de nutrientes, como as concentrações sais e açucares podem ser críticas no processo de crescimento de plântulas (Moraes et al. 2012). A baixa concentração de sais e sacarose no meio é um fator importante na indução do crescimento de raízes e parte aérea, bem como (Monfort et al. 2015). No presente trabalho os tratamentos não contiveram acréscimo de nutrientes no meio de cultivo, e os valores de massa fresca parecem estar mais relacionados a espécie.

Segundo os estudos de Cota-Sanchez \& Abreu (2007), as taxas de mortalidade e a vulnerabilidade do desenvolvimento nos estágios iniciais estão relacionados com o fornecimento de nutrientes e disponibilidade de água. Estudos feitos em plântulas de Epiphyllum phyllanthus (L.) Haw., uma Cactaceae epifítica, por Almeida et al. (2013), e em plântulas de Trichocereus candicans Britton \& Rose, Cactaceae terrestre (Cenizo et al. 2013), mostraram que essas plantas apresentaram crescimento mais significativo da parte aérea até os 60 dias de desenvolvimento. Assim como nos resultados destes autores, nas espécies aqui estudadas, o estabelecimento de plântulas e seu desenvolvimento nos 60 dias de cultivo são críticas, pois foi constatada a vulnerabilidade e a mortalidade nas fases iniciais de desenvolvimento. As plântulas morreram após 60 dias de cultivo em água, pois as reservas de nutrientes se exauriram, apontando a necessidade de transferência dessas plântulas para substratos férteis antes desse período. Estudos sobre a sobrevivência de 
plântulas de Cactaceae indicaram que após uma semana de cultivo em água, seu transplante para meios ou substratos que disponibilizem nutrientes e água, é fundamental para seu estabelecimento (Cota-Sanchez \& Abreu 2007; Almeida et al. 2013). Na germinação e desenvolvimento de plântulas de E. phyllanthus, as duas primeiras semanas mostraram-se críticas na sobrevivência das plântulas, pois ocorreu uma elevada incidência de mortalidade (50\%), indicando a vulnerabilidade das fases iniciais de desenvolvimento (Almeida et al. 2013).

$\mathrm{O}$ teor de clorofila $\mathrm{b}$ foi maior que o teor de clorofila a em todas as espécies estudadas. O teor de carotenóides foram diferentes entre as espécies. Os maiores teores de clorofilas $a, b$, totais e carotenóides foram observados em $R$. teres, seguidos de L. cruciforme e $R$. neves-armondii (Tab. 3). Em condições de estresse abiótico como déficit hídrico, a taxa de biossíntese de clorofilas tende a diminuir (Giri et al. 2013). Os teores de clorofila total nas plantas in vitro, são mais baixos que quando encontrados na natureza e podem ser explicados pela dependência da única fonte de carbono do meio de cultivo (López-Escamilla et al. 2016). Os teores de carotenóides, são sempre mais altos em Cactaceae na natureza do que in vitro, como em Melocactus zehntneri (Britton \& Rose) Luetzelburg e Opuntia ficus-indica L. (Mill.), pelo fato da necessidade de defesa de ataques de pragas, doenças e dos raios de sol (Medina-Torres et al. 2011; Nunes et al. 2016). Porém, a quantificação de carotenóides são difíceis de comparar na literatura especializada, porque estão muito influenciados por fatores como condições genética, solo e clima, e as demais técnicas de desenvolvimento in vitro como a preparação do substrato (Nunes et al. 2016). Embora as três espécies investigadas tenham sido submetidas as mesmas condições de germinação e cultivo, os resultados relativos aos teores de clorofila e carotenóides indicam que $R$. teres foi mais resistente ao cultivo in vitro em relação às outras duas espécies.

As plântulas de R. neves-armondii (Fig. 4a-c), R. teres (Fig. 4d-f) e L. cruciforme (Fig. 4g-i), 60 dias após as sementes serem colocadas para germinar em água, apresentaram coloração verde uniforme, hipocótilo suculento, cilíndrico, cotilédones com ápices pontiagudos e sistema radicular. As plântulas de $R$. neves-armondii e $R$. teres, apresentam o epicótilo evidente já aos 15 dias de cultivo (Figs. 4a,d), enquanto nas plântulas de $L$. cruciforme ainda não haviam desenvolvido até 60 dias de cultivo (Fig. 4i). As plântulas de R. teres (Fig. 5b) e L. cruciforme (Fig. 5d), 60 dias após as sementes serem colocadas para germinar em agar, não evidenciaram o desenvolvimento do epicótilo, mas apresentaram morfologia semelhante ao hipocótilo de sementes germinadas em água. As sementes de $R$. neves-armondii não germinaram neste substrato. As plântulas de R. teres e L. cruciforme, aos 30 dias, mostraram-se constituídos por raiz (Fig. 5a,c). Os resultados sugerem que o cultivo apenas em água seja mais adequado que em ágar, pois favoreceu a germinação e desenvolvimento das plântulas de $R$. neves-armondii, $R$. teres e L. cruciforme. $\mathrm{O}$ processo da germinação está ligado diretamente ao movimento de água através dos tecidos que envolvem a semente (Santos et al. 1992; Carvalho \& Nakagawa 2000). Os autores mencionam que, a presença de sais interfere no potencial hídrico do meio de cultura, reduzindo o gradiente de potencial entre o meio de cultura e a superfície da semente, restringindo a captação de água pela semente influenciando significativamente a germinação. Quando o potencial osmótico da solução é inferior (mais negativo) ao das células do embrião, ocorre a redução da porcentagem de germinação e do desenvolvimento de plântulas, como relatado para sementes de soja (Santos et al. 1992), pepino (Torres et al. 2000), Adenanthera pavoniana (Fonseca \& Perez 2001) e cenoura (Lopes \& Dias 2004).

Os hipocótilos de $R$. neves-armondii já eram evidenciados aos 15 dias, após serem colocados para germinar em água, desenvolvendo-se mais nos períodos seguintes (Fig. 4a). Os hipocótilos mostraram-se providos de espinhos emergentes de aréolas. Embora em $R$. teres já podia ser visto o epicótilo, este manteve-se pouco desenvolvido mesmo aos 60 dias (Fig. 4f), não exibindo ainda a presença de espinhos. Em L. cruciforme (Fig. 4i) não ocorreu o desenvolvimento de epicótilo, porém a emergência de raros espinhos, na região do nó cotiledonar pode ser constatada aos 60 dias. O hipocótilo das três espécies apresentou-se suculento. Características semelhantes também são descritas por Secorun \& Souza (2011) para hipocótilos em plântulas de Cactaceae com 50 dias de desenvolvimento. Nas espécies estudadas pelos autores, as plântulas apresentam epicótilo suculento (filocládio), aréolas com longos espinhos pontiagudos e tricomas curtos. A raiz primária ramificou-se a partir dos 15 dias em todas as espécies estudadas (Figs. 4a,d,g). O colo foi evidente e de coloração esbranquiçada (Fig. 4).

Sementes das três espécies foram inoculadas em ágar, porém $R$. neves-armondii não mostrou 

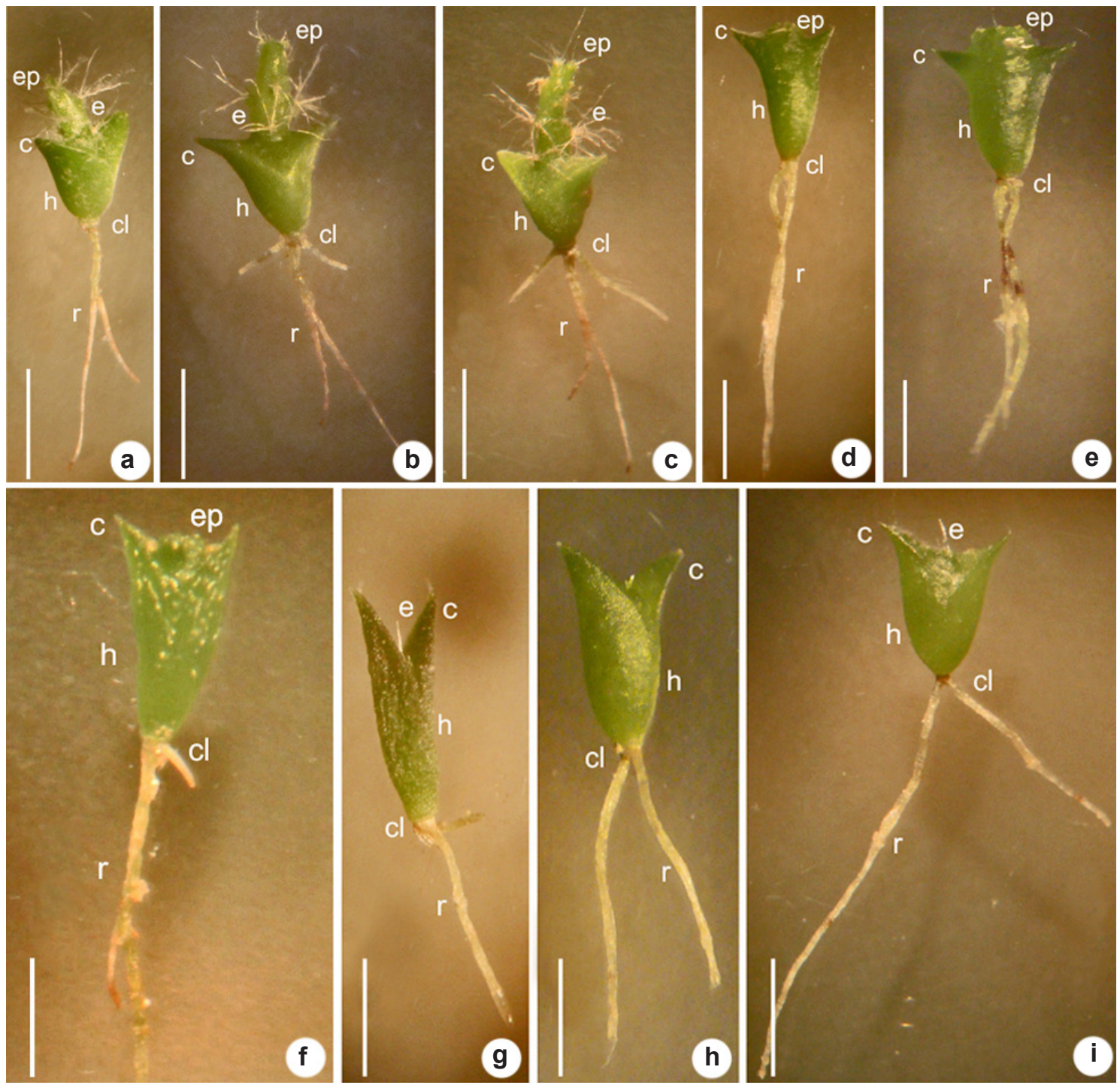

Figura 4 - Plântulas germinadas em água - a-c. Rhipsalis neves-armondii; d-f. Rhipsalis teres; g-i. Lepismium cruciforme. a,d,g. aos 15 dias; b,e,h. aos 30 dias; c,f,i. aos 60 dias. Barras: 2 mm. Legenda: e - espinhos; c - cotilédones; cl - colo; h - hipocótilo; $\mathrm{r}$ - raiz.

Figure 4 - Seedlings germinated in water - a-c. Rhipsalis neves-armondii; d-f. Rhipsalis teres; g-i .Lepismium cruciforme. a,d,g. at 15 days; b,e,h. at 30 days; c,f,i. at 60 days. Bars: 2 mm. Caption: e - thorns; c - cotyledons; cl - collar; h - hypocotyl; r - root.

reação positiva ao processo germinativo. Sendo assim, as análises morfológicas e anatômicas em ágar restringiram-se às plântulas de $R$. teres e $L$. cruciforme. As plântulas de $R$. teres e $L$. cruciforme, aos 30 dias (Figs. 5 a,c), mostraramse constituídos por raiz e hipocótilo, com formação de cotilédones, porém aos 60 dias (Figs. 5b,d), ainda não podia ser evidenciado o desenvolvimento do epicótilo. O hipocótilo apresentou-se verde e suculento, alargando-se acropetamente, devido à formação dos cotilédones, estes com extremidade pontiaguda (Fig. 5). Estas características morfológicas observadas são semelhantes ao registrado por Loza-Cornejo et al. (2003), Almeida et al. (2009) e Secorun \& Souza (2011), para espécies de Cactaceae. Conforme os autores, as plântulas mostram uma redução considerável do comprimento e um aumento na suculência quando comparados com as eudicotiledôneas.

Os hipocótilos de $R$. teres (Fig. 6a) e $L$. cruciforme (Fig. 6b) apresentaram epiderme 

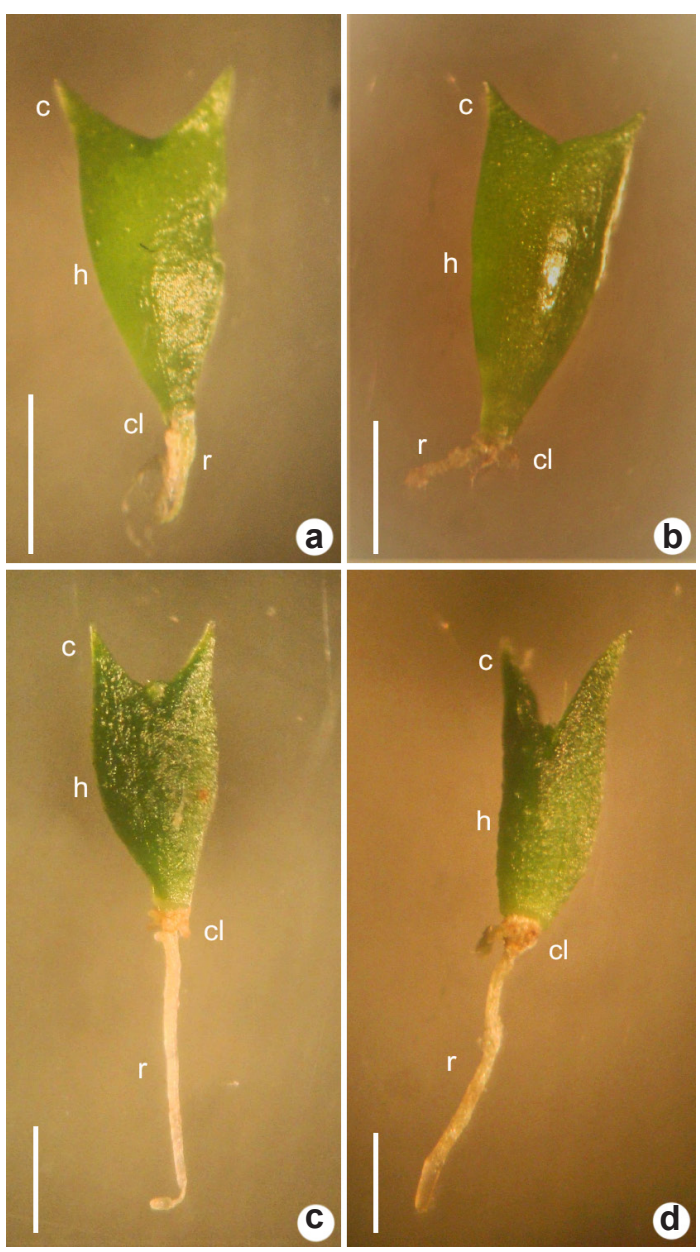

Figura 5 - Plântulas germinadas em agar - a-b. Rhipsalis teres; c-d. Lepismium cruciforme. a,c. aos 30 dias; b,d. aos 60 dias. Barras: 2 mm. Legenda: c cotilédones; cl - colo; h - hipocótilo; r- raiz.

Figure 5 - Seedlings germinated in agar - a-b. Rhipsalis teres; c-d. Lepismium Cruciforme. a,c. at 30 days; b,d. at 60 days. Bars: $2 \mathrm{~mm}$. Caption: c- cotyledons; cl - collar; h- hypocotyl; r - root.

unisseriada, com cutícula espessa, e parênquima aquífero constituindo o córtex. Nas duas espécies aqui estudadas, as características correspondem aquelas descritas por Terrazas \& Arias (2003), Calvente et al.(2008) e Torres-Boeger et al. (2010). Resultados relativos às características histológicas do hipocótilo de $R$. teres e L. cruciforme, aos 30 dias (Figs. 6c,d,e) e aos 60 dias (Figs. 6f,g), após as sementes serem colocadas para germinar em ágar, revelaram algumas variações estruturais com o desenvolvimento.

A epiderme apresentou-se unisseriada nos hipocótilos de R. teres e L. cruciforme (Fig. 6h,i,j). Nas plântulas de $R$. teres, aos 30 dias de cultivo em ágar, constatou-se que a parede periclinal externa das células epidérmicas mostrava-se convexa região basal do hipocótilo (Fig. 6h) e plana na região média (Fig. 6i) e, aos 60 dias de cultivo, a convexidade foi observada ao longo de todo hipocótilo. Em $L$. cruciforme, aos 30 dias, a parede periclinar externa das células epidérmicas era plana (Fig. 6j), porém tornou-se convexa aos 60 dias. Em ambas as espécies, nos dois períodos analisados, a cutícula mostrou-se espessa (Figs. 6h-j) e os estômatos, do tipo paracítico, estavam no mesmo nível das demais células epidérmicas (Figs. 6j,1,m). Terrazas \& Arias (2003) também constataram estômatos do tipo paracítico em Cactaceae, porém Barthlott \& Hunt (1993), para espécies de Cactaceae, e Secorun \& Souza (2011), mas especificamente para L. cruciforme e espécies de Rhipsalis, referem o tipo paralelocítico. A cutícula espessa constitui cacterística xérica que favorece a economia hídrica, pois como epífitas, embora protegidas de excessiva irradiação solar, tem limitação de disponibilidade de água. Loza-Cornejo \& Terrazas (2003) ressaltam que a cutícula fornece uma interface de proteção importante para a planta-ambiente.

$\mathrm{O}$ córtex do hipocótilo estava preenchido por parênquima aquífero (Figs. 6a-g), com células clorofiladas e conteúdo mucilaginoso. Barthlott \& Hunt (1993), Mauseth (2006) e Secorun \& Souza (2011) também mencionam a presença de tecido de reserva hídrica, contendo mucilagem, no hipocótilo de espécies de Cactaceae. O parênquima aquífero, assim como a cutícula espessa, também representa importante cacterística xérica que desempenha importante função na economia hídrica (Lambers et al. 1998). Em $R$. teres, o formato do hipocótilo mostrou-se mais arredondado na base (Fig. 6c) e dilatado na região média (Fig. 6d) em decorrência do surgimento dos cotilédones. Em L. cruciforme o formato variou em decorrência do desenvolvimento, apresentando, na região média do hipocótilo, um formato arredondado aos 30 dias (Fig. 6e) e achatado aos 60 dias (Fig. 6g). O sistema vascular, na região basal (Fig. 6k), zona de transição entre o hipocótilo e raiz, mostrou dois cordões de floema, entre os quais se localizava o xilema exarco, o que também foi referido por Secorun \& Souza (2011) para Rhipsalis cereuscula Haw., Rhipsalis floccosa Salm-Dyck e L. cruciforme. Na região média do hipocótilo estas características mantiveram-se nas espécies analisadas, não tendo sido evidenciada a condição endarca do xilema, como observado por Secorun \& Souza (2011), diferença que indica que transição da estrutura xilemática de exarca para endarca pode, na 


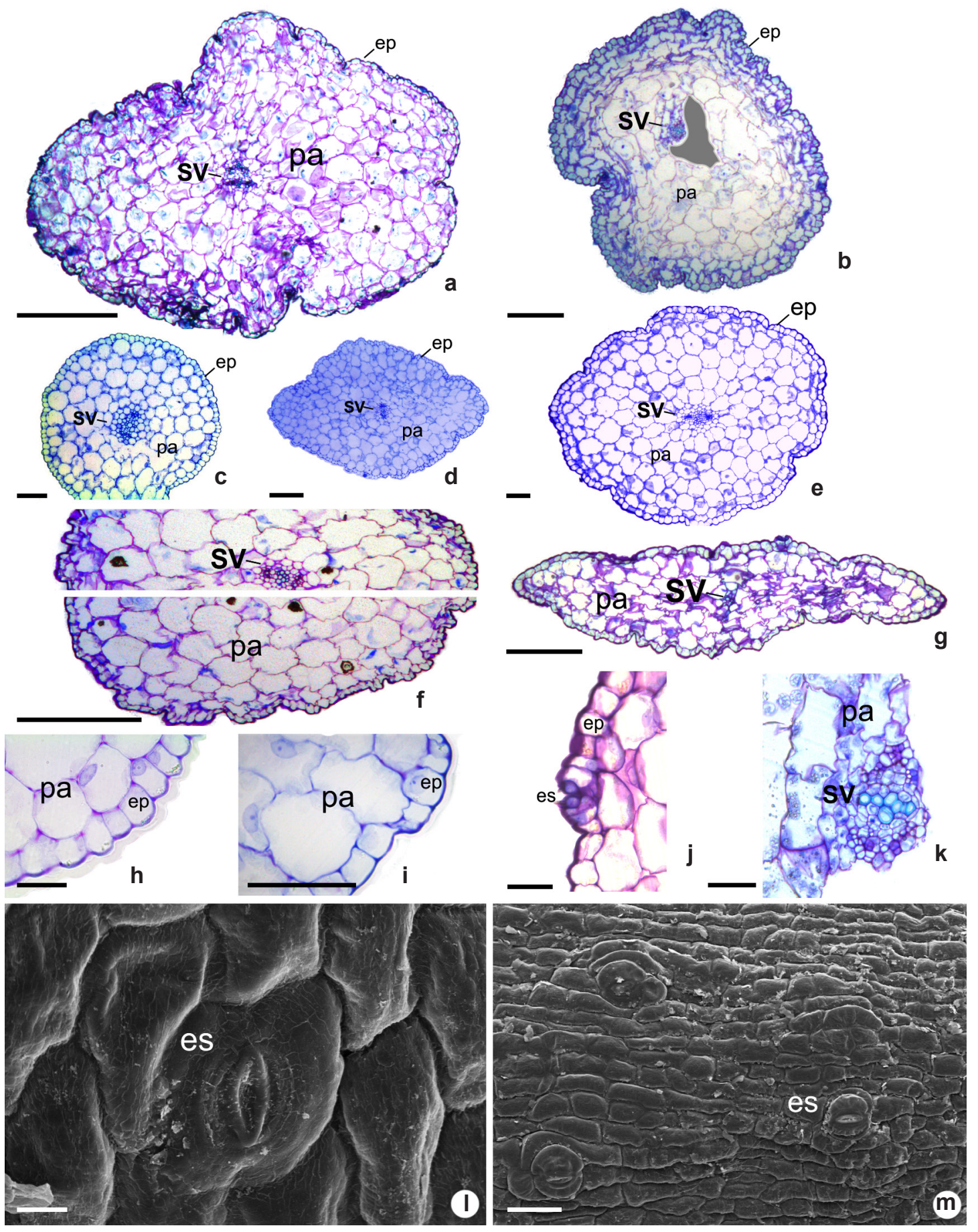

Figura 6 -a-k. Secções transversais de hipocótilo, em microscopia óptica; 1-m. vista frontal em microscopia eletrônica de varredura. a,c,d,f,h,i,l. Rhipsalis teres; b,e,g,j,k,m. Lepismium cruciforme. a,b,k. Plântulas aos 60 dias de cultivo em água; c-e,h-j,l-m. plântulas aos 30 dias de cultivo em ágar; f,j. plântulas aos 60 dias de cultivo em ágar. a,d-g,i. Região média; b,c,h,k. região basal. Legenda: ep - epiderme; es - estômato; pa - parênquima aquífero; sv - sistema vascular. Barras: $\mathrm{a}, \mathrm{k}=100 \mu \mathrm{m} ; \mathrm{b}, \mathrm{e}, \mathrm{g}=300 \mu \mathrm{m} ; \mathrm{c}, \mathrm{h}-\mathrm{j}, \mathrm{m}=50 \mu \mathrm{m} ; \mathrm{d}=200 \mu \mathrm{m} ; \mathrm{f}=30 \mu \mathrm{m} ; 1=10 \mu \mathrm{m}$.

Figure 6 - a-k. Hypocotyl cross-sections under light microscopy; 1-m. front view in scanning electron microscopy. a,c,d,f,h,i,l. Rhipsalis teres; b,e,g,j,k,m. Lepismium cruciforme. a,b,k. Seedlings at 60 days of cultivation in water; c-e,h-j,l-m. seedlings at 30 days of agar culture; f,j. seedlings at 60 days of agar culture. a,d-g,i. Middle region; b,c,h,k. basal region. Caption: ep - epidermal; es -s tomata; pa water-storage parenchyma; sv - vascular system. Bars: a,k =100 $\mu \mathrm{m} ; \mathrm{b}, \mathrm{e}, \mathrm{g}=300 \mu \mathrm{m} ; \mathrm{c}, \mathrm{h}-\mathrm{j}, \mathrm{m}=50 \mu \mathrm{m} ; \mathrm{d}=200 \mu \mathrm{m} ; \mathrm{f}=30 \mu \mathrm{m} ; 1=10 \mu \mathrm{m}$. 
mesma espécie, ocorrer em regiões mais basais ou mais apicais do hipocótilo. Terrazas \& Arias (2003) observaram a presença de fibras junto ao floema no hipocótilo de espécies de Rhipsalideae, o que não foi constatado nas espécies analisadas até 60 dias de cultivo em ágar. Considerando o conjunto de atributos morfológicos analisados, as espécies estudadas de Lepismum mostram que a epiderme unisseriada coberta por cutícula, córtex clorofilado, contendo células mucilaginosas e parênquima aquífero são características selecionadas pelas condições ambientais, apesar do xeromorfismo histórico do grupo (Boeger et al. 2010). Comentam os autores que, estudos adicionais, em diferentes condições ambientais, tais como, a disponibilidade luz e água, podem elucidar o grau de plasticidade morfológica nas características analisadas e podem ajudar na compreensão de estratégias de adaptação de espécies de Cactaceae epífitas.

Nas plantas adultas de $R$. teres, o caule mostrou forma aproximadamente cilíndrica constituído por epiderme, córtex, cilindro vascular e medula (Fig. 7a). A epiderme apresentou-se uniestratificada e com cutícula espessa (Fig. 7b). Cutícula espessa é uma característica da subfamília Cactoideae (Mauseth et al. 2002; Calvente et al. 2008; Dettke \& Milaneze-Gutierre 2008). Os estômatos formavam leve depressão na superfície epidérmica e apresentaram-se do tipo ciclocítico, com células-guarda circundadas por células subsidiárias (Figs. 7c,d). O córtex estava constituído por amplo parênquima aquífero (Fig. 7b), constituído por células clorofiladas e contendo mucilagem, intermeado por idioblastos com drusas. Na região mais interna do córtex ocorreram feixes corticais, (Fig. 7e). $\mathrm{O}$ cilindro vascular estava formado por feixes vasculares (Fig. 7a) do tipo colateral e com calota de fibras delimitando externamente o floema (Fig. 7e). As fibras associadas ao floema são caracteres já registrados para a subfamília Cactoideae (Gibson \& Nobel 1986; Loza-Cornejo \& Terrazas 2003; Terraza \& Arias 2003; Mauseth 2006). A medula estava preenchida por tecido parenquimático.

$\mathrm{O}$ caule de L. cruciforme mostrou-se com forma triangular (Fig. 8a), decorrente da formação das três expansões laterais (alas) que percorrem o caule longitudinalmente. A epiderme apresentou-se uniestratificada (Fig. 8b,c) e revestida por cutícula espessa. Os estômatos estavam posicionados no mesmo nível das demais células epidérmicas (Fig. 8c), sendo do tipo ciclocítico (Fig. 8e). Presença de estômatos com arranjo no mesmo nível ou aprofundados em relação às demais células epidérmicas são referidos por Terraza \& Arias (2003) para a subfamília Cactoideae. Contornando o complexo estomático foi constatada grande deposição de ceras epicuticulares (Fig. 8f). A região mais externa do córtex (hipoderme) constituiu-se de colênquima (Fig. 8c). O tecido subepidérmico de caules de Cactaceae tem sido descrito como hipoderme colenquimatosa (Gibson \& Nobel 1986; Loza-Cornejo \& Terrazas 2003). Mas a maior porção do córtex estava preenchida por parênquima aquífero (Fig. 8a), formado por parênquima clorofiliano, células mucilaginosas e mais internamente, pelo parênquima aquífero, entremeadas por feixes corticais espalhados por todo o córtex (Fig. 8b). O cilindro central, mesmo em regiões mais jovens, já exibia a presença de estrutura vascular secundária, com anel contínuo de xilema e floema, intercalados por câmbio vascular, e fibras acompanhando externamente o floema (Fig. 8d). O cilindro vascular bem desenvolvido com estruturação secundária é característico de Cactaceae (Mauseth 2006), entretanto, em $R$. teres isto não foi constatado, possivelmente por terem sido usadas amostras caulinares de regiões mais apicais. A medula mostrou-se constituída por células parenquimáticas (Fig. 8d).

As espécies $R$. teres e L. cruciforme apresentaram diferenças morfológicas e anatômicas entre o hipocótilo da plântula e o caule adulto. A morfologia das plântulas é totalmente diferente com caule adulto. O hipocótilo apresenta-se liso e curto, sem a presença de aréolas e espinhos como ocorrem em caules de plantas adultas. Também não apresenta colunas ou podários como conhecidos nos caules em Cactaceae.

Já referente a parâmetros anatômicos, a presença de cutícula espessa em plântulas e caule adulto são características marcantes de Cactaceae. São consideradas características de espécies de ambientes xéricos (Loza-Cornejo \& Terrazas 2003; Terrazas \& Arias 2003; Mauseth 2006). A presença da cutícula espessa desde a fase de plântula até a fase adulta favorece o equilíbrio hídrico interno, o que também é proporcionado pela presença de parênquima aquífero.

Células epidérmicas apresentaram-se com parede periclinal externa convexa, característica comum em Cactaceae (Loza-Cornejo \& Terrazas 2003). Conforme autores, a forma da parede celular periclinal convexa na epiderme, ajudam evitar a perda de água, uma vez que aumentam a distância entre o ambiente externo e os tecidos subjacentes. 


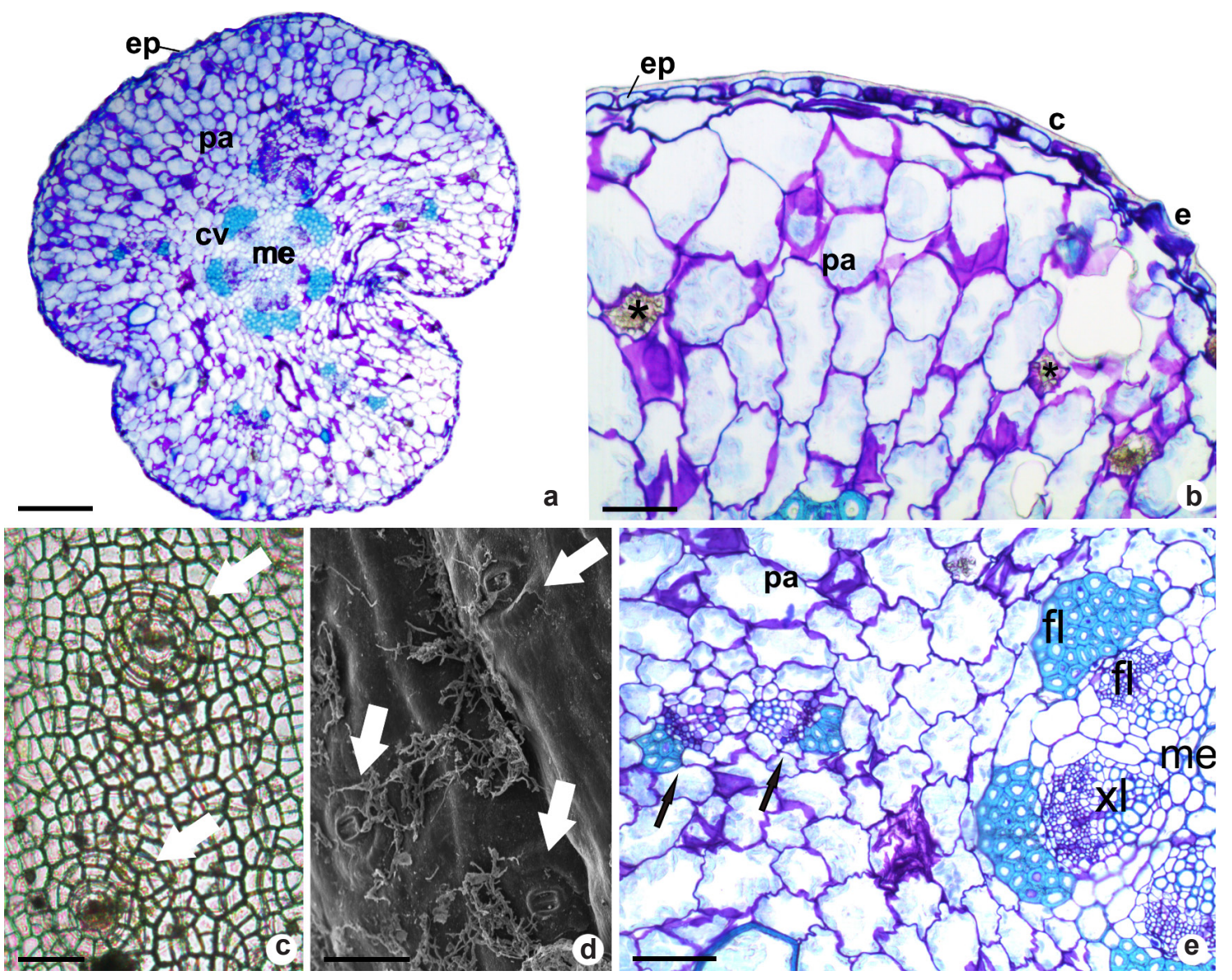

Figura 7 - Caule de Rhipsalis teres, secções transversais em microscopia óptica (a-b,e), vistas frontais da epiderme em microscopias óptica (c) e eletrônica de varredura (d) - a. aspecto geral do caule com forma cilíndrica; b. detalhe dos tecidos de revestimento e corticais, com idioblastos contendo drusas (*); c-d. estômatos ciclocíticos (setas) formando leve depressão na superfície epidérmica; e. detalhe da região interna do córtex com traços foliares (setas) e feixes vasculares colaterais do cilindro central. Legenda: c - cutícula; e - estômato; ep - epiderme; fi - fibras; fl floema; pa - parênquima aquífero; me - medula; cv - cilindro vascular; $x \mathrm{l}$ - xilema. Barras: $\mathrm{a}=300 \mu \mathrm{m} ; \mathrm{b}, \mathrm{c}, \mathrm{e}=100$ $\mu \mathrm{m} ; \mathrm{d}=50 \mu \mathrm{m}$.

Figure 7 - Stem of Rhipsalis teres, cross-sections under light microscopy (a-b,e), frontal views of the epidermis under optical microscopy (c) and scanning electron (d) - a. general appearance of stem with cylindrical shape; b. detail of lining and cortical tissues, with idioblasts containing drusen $(*)$; c-d. ciclocytic stomata (setae) forming mild depression on the epidermal surface; e. detail of the internal cortex region with foliar traces (arrows) and collateral vascular bundles of the central cylinder. Caption: c - cuticle; e - stomata; ep - epidermis; fi - fibers; fl - phloem; pa - water-storage parenchyma; me - marrow; cv- vascular cylinder; $x 1$ - xylem. Bars: $a=300 \mu$ m; b, c, e = 100 $\mu \mathrm{m} ; \mathrm{d}=50 \mu \mathrm{m}$.

As duas espécies estudadas apresentam estômatos paracíticos nos hipocótilos e ciclocíticos nos caules adultos. Estes dois tipos estomáticos são referidos para espécies de Cactaceae epífitas por Terrazas \& Arias (2003) e Mauseth (2006). Cabe, entretanto ressaltar a maior complexidade da estrutura estomática na planta mais desenvolvida, o que deve estar relacionado com uma maior eficiência funcional.
O hipocótilo das plântulas e o caule das Cactaceae epífitas mostram-se suculentos, com presença de parênquima aquífero clorofilado no córtex (Calvente et al. 2008; Calvente et al. 2010). Em R. teres e L. cruciforme, também foi observado hipocótilo suculento e parênquima aquífero clorofilado na região cortical, confirmando as características em plântulas de Cactaceae epifíticas estudadas por outros autores anteriormente 

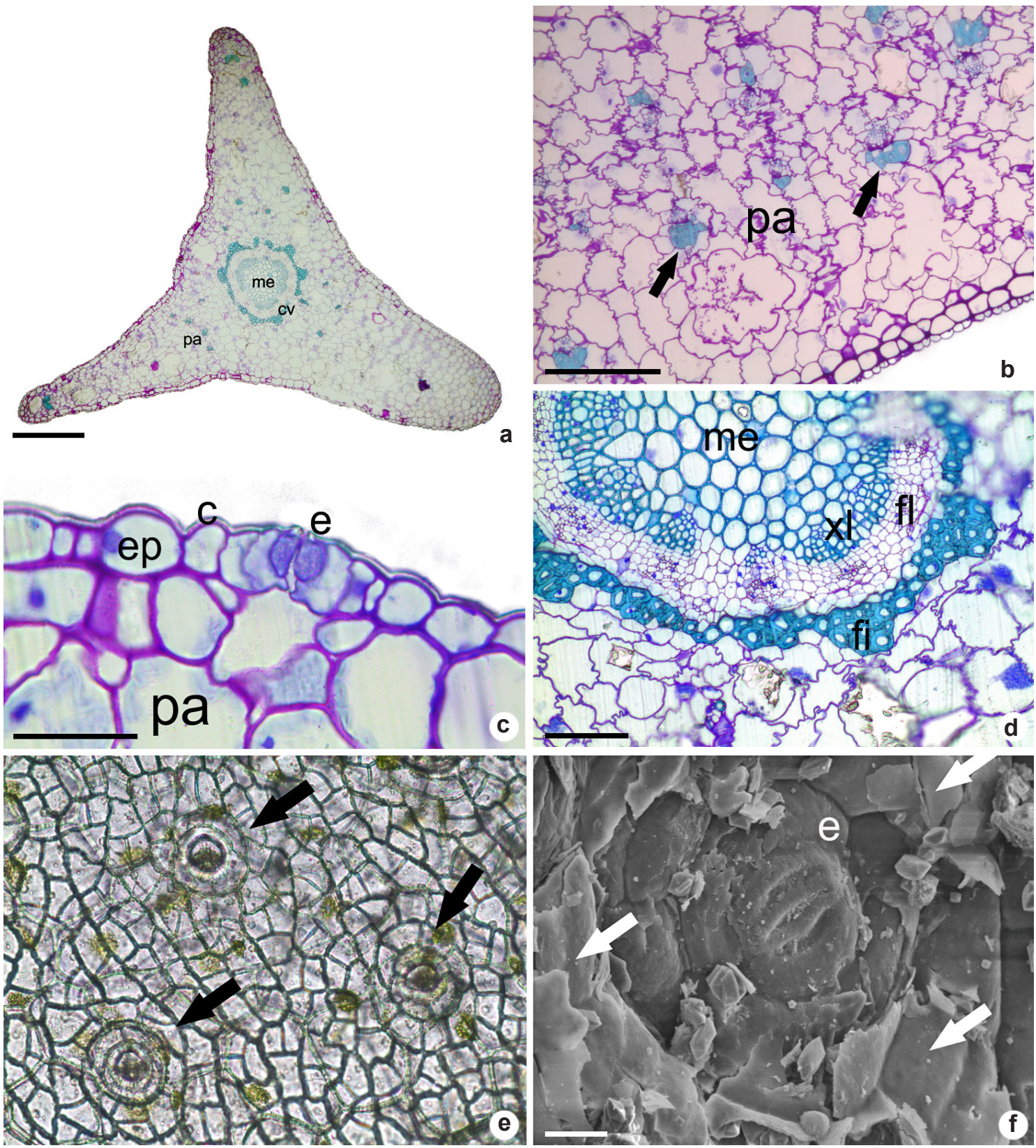

Figura 8 - Caule de Lepismium cruciforme - a-d. secções transversais em microscopia óptica; e-f. vistas frontais em microscopias óptica (e) e eletrônica de varredura (f). a. Aspecto geral do caule; b. detalhe dos tecidos periféricos, com feixes de fibras (setas) entre as células do parênquima aquífero; c. detalhe da epiderme, com presença de estômato no mesmo nível das demais células epidérmicas, e hipoderme; d. detalhe do cilindro vascular e tecidos corticais e medulares; e. estômatos ciclocíticos (setas); f. ceras epicutilares (setas) circundando estômato. Legenda: c - cutícula; e - estômato; ep - epiderme; fi - fibras; fl - floema; pa- parênquima aquífero; me - medula; xl - xilema. Barras: a = $300 \mu \mathrm{m} ; \mathrm{b}-\mathrm{e}=100 \mu \mathrm{m} ; \mathrm{f}=20 \mu \mathrm{m}$.

Figure 8 - Stem of Lepismium cruciforme - a-d. cross sections in light microscopy; e-f. frontal views in optical microscopy (e) and scanning electron (f). a. General appearance of the stem; b. detail of the peripheral tissues, with bundles of fibers (arrows) between the cells of the hydrenchyma; $c$. detail of the epidermis, with presence of stomata on the same level as the other epidermal cells, and hypodermis; d. detail of vascular cylinder and cortical and medullary tissues; e. cyclocytic stomata (arrows); f. epicutilar waxes (arrows) circling stomata. Legend: c - cuticle; e - stomata; ep-epidermis; fi - fibers; fl - phloem; pa - water-storage parenchyma; me - medulla; $\mathrm{xl}$ - xylem. Bars: $\mathrm{a}=300 \mu \mathrm{m} ; \mathrm{b}-\mathrm{e}=100 \mu \mathrm{m} ; \mathrm{f}=20 \mu \mathrm{m}$. 
como Rojas-Aréchiga \& Vázquez-Yanes (2000), Cota-Sanchez \& Abreu (2007), Loza-Cornejo et al. (2008) e Secorun \& Souza (2011). A forma do hipocótilo entre as espécies estudadas apresentaram-se semelhantes, com formato cilíndrico na região mais basal alargando em direção aos cotilédones na região apical. $\mathrm{O}$ caule adulto de $R$. teres apresentou forma cilíndrica, diferente em $L$. cruciforme que apresentou forma trilobada ou colunar como também observado nos estudos de algumas espécies dos gêneros de Rhipsalis e Lepismium feitos por Mauseth (2006) e Calvente et al. (2008). As plântulas R. teres e $L$. cruciforme tem a sua forma muito parecidas até os 60 dias de análises de desenvolvimento, porém na fase adulta o caule é distinto.

\section{Conclusão}

As espécies apresentaram diferenças em padrões estratégicos germinativos e no desenvolvimento em água e em agar. As sementes de $R$. neves-armondi e $R$. teres precisam de tempo maior para germinar em água que sementes de Lepismium cruciforme. A germinação de $L$. cruciforme em agar foi mais rápida.

O desenvolvimento das plântulas de $R$. neves-armondi e $R$. teres foi mais significativo 15 dias após as sementes serem colocadas para germinar. L. cruciforme teve desenvolvimento mais significativo após 30 dias das sementes serem colocadas para germinar.

Germinação em água apontou ser mais eficiente que em agar, onde apresentou uma taxa germinativa baixa. Ainda, o meio de cultivo em agar gerou uma perda de sementes até o período de 60 dias.

O estudo revelou a importância de teste de novos substratos e meios nutritivos em composições diferentes para promover a germinação e desenvolvimento.

\section{Agradecimentos}

Ao Laboratório Central de Microscopia Eletrônica (LCME) da Universidade Federal de Santa Catarina a disponibilidade do uso de suas estruturas. Ao Herbário "Barbosa Rodrigues" o apoio em minha pesquisa.

\section{Referências}

Almeida OJG, Paoli AAS, Souza LA \& Hugo CotaSánchez JH (2013) Seedling morphology and development in the epiphytic cactus Epiphyllum phyllanthus (L.) Haw. (Cactaceae: Hylocereeae). Journal of the Torrey Botanical Society 140: 196-214.

Almeida OJG, Souza LA \& Moscheta SI (2009) Morfoanatomia da plântula de indivíduos somaclones de Cereus hildmannianus Schumann (Cactaceae). Boletín de la Sociedad Latinoamericana y del Caribe Cactáceas y otras Suculentas 6: 29-35.

Anderson EF (2001) The cactus family. Timber Press, Portland. 776p.

Barbedo CJ, Bilia DAC \& Figueiredo-Ribeiro RCL (2002) Tolerância a dessecação e armazenamento de sementes de Caesalpinia echinata Lam. (paubrasil). Revista Brasileira de Botânica 25: 431-439.

Barber J \& Anderson B (1992) Too much of a good thing: light can be bad for photosynthesis. Trends in Biochemical Science 17: 61-66.

Barthlott W \& Hunt DR (1993) Cactaceae. In: Kubitzki K, Rohwer JG \& Bittrich V (eds.) The families and genera of vascular plants. Flowering plants. Dicotyledons: Magnoliid, Hamamelid and Caryophyllid families. Springer-Verlag, Berlin. Pp. 161-197.

Barthlott W \& Hunt DR (2000) Seed-diversity in the Cactaceae: subfamily Cactoideae. Vol. 5. Succulent Plant Research, Sherborne. 173p.

Beck CB (2005) An introduction to plant structure and development: plant anatomy for the twenty-first century. Cambridge University Press, Cambridge. $464 \mathrm{p}$.

Boeger MRT, Soffiatti P, Souto MAG, Budchen M, Bagatini KP \& Dalforno M (2010) Functional morphology of two Lepismium species (Rhipsalideae, Cactaceae). Revista Mexicana de Biodiversidad 81: 393-400.

Brasil (2009) Regras para análise de sementes. Ministério da Agricultura, Pecuária e Abastecimento, Secretaria de Defesa Agropecuária. Brasília. 395p.

Bregman R \& Bouman F (1983) Seed germination in Cactaceae. Botanical journal of the Linnean Society 83: 357-374.

Cavalcante A, Teles M \& Machado M (2013) Cactos do semiárido do Brasil: guia ilustrado. Ministério da Ciência, Tecnologia e Inovação, Campina Grande. $103 p$.

Calvente A, Regina HP, Andreata RHP \& Vieira RC (2008) Stem anatomy of Rhipsalis (Cactaceae) and its relevance for taxonomy. Plant Systematics and Evolution 276: 1-7.

Calvente AM (2010) Filogenia molecular, evolução e sistemática de Rhipsalis (Cactaceae). Tese de Doutorado. Universidade de São Paulo, São Paulo. $185 \mathrm{p}$.

Cenizo VJ, Mazzola MB, Corró Molas BM \& Kin AK (2013) Características morfológicas y anatómicas de las plântulas de Trichocereus candicans 
(Cactaceae). Boletín de la Sociedad Argentina de Botánica 48: 443-451.

Cota-Sanchez JH \& Abreu DD (2007) Vivipary and offspring survival in the epiphytic cactus Epiphyllum phyllanthus (Cactaceae). Journal of Experimental Botany 58: 3865-3873.

Dettke GA \& Milaneze-Gutierre MA (2008) Anatomia caulinar de espécies epífitas de Cactaceae, subfamília Cactoideae. Hoehnea 35: 583-595.

Dickson WC (2000) Integrative plant anatomy. Academic Press, London. 533p.

Eggli U (1984) Stomatal types of Cactaceae. Plant Systematics and Evolution 146: 197-214.

Flores J, Jurado E \& Jiménez-Bremont JF (2008) Breaking seed dormancy in specially protected Turbinicarpus lophophoroides and Turbinicarpus pseudopectinatus (Cactaceae). Plant Species Biology 23: 43-46.

Gibson AC \& Nobel PS (1986) The cactus primer. Haward University Press, Cambridge. 286p.

Giri S, Shrivastava D, Deshmukh K \& Dubey P (2013) Effect of air pollution on chlorophyll content of leaves. Current Agriculture Research Journal 2: 93-98.

Godínez-Álvarez H, Valverde T \& Ortega-Baes P (2003) Demographic trends in the Cactaceae. The Botanical Review 69: 173-203.

Guillén S, Benítez J, Martínez-Ramos M \& Casas A (2009) Seed germination of wild, in situ-managed, and cultivated populations of columnar cacti in the Tehuacán-Cuicatlán Valley, Mexico. Journal of Arid Environments 73: 407-413.

Hoppe JM, Genro CJM, Vargas CO, Floriano EP, Reis ER, Fortes FO, Müller I, Farias JA, Calegari L \& Dacosta LPE (2004) Produção de sementes e mudas florestais. Caderno Didático 1. 2a ed. UFSM, Santa Maria. 388p.

Horridge GA \& Tamm SL (1969) Critical point drying for scanning electron microscopy study of ciliary motion. Science 163: 817-818.

Lambers J, Chapin FS \& Pons TL (1998) Plant physiological ecology. Springer Verlag, New York. $540 \mathrm{p}$.

Lichtenthaler HK (1987) Chlorophylls and carotenoids: pigments of photosynthetic biomembrane. Methods in Enzymology 148: 350-382.

López-Escamilla AL, López-Herrera M \& Loaiza-Alanís C (2016) Efecto de diferentes agentes gelificantes en la germinación y desarrollo I de plántulas de Echinocactus platyacanthus Link et Otto (Cactaceae). Polibotánica 42: 153-166.

Loza-Cornejo S \& Terrazas T (2003) Epidermal and hypodermal characteristics in North American Cactoideae (Cactaceae). Journal of Plant Research 116: 27-35.
Loza-Cornejo S, Terrazas T, López-Mata L \& Trejo C (2003) Características morfo-anatómicas y metabolismo fotosintético en plántulas de Stenocereus queretaroensis (Cactaceae): su significado adaptativo. Interciencia 28: 83-89.

Loza-Cornejo S, López-Mata L \& Terrazas T (2008) Morphological seed traits and germination of six species of Pachycereeae (Cactaceae). Journal of the Professional Association for Cactus Development 10: 71-84.

Mauseth JD (1988) Plant anatomy. The Benjamin. Cummings, Menlo Park. 560p.

Mauseth JD (2006) Structure-function relationships in highly modified shoots of Cactaceae. Annals of Botany 98: 901-926.

Mauseth JD, Kiesling R \& Ostolaza CN (2002) A cactus odyssey. Journey in the wilds of Bolivia, Peru, and Argentina. Timber Press, Portland. 306p.

Medina-Torres L, Gallegos-Infante JA, Rocha-Guzman NE, Herrera-Valencia EE, Calderas F \& JiménezAlvarado R (2011) Study of the antioxidant properties of extracts obtained from nopal cactus (Opuntia ficus-indica) cladodes after convective drying. Journal of the Science of Food and Agriculture 91: 1001-1005.

Monfort LEF, Pinto JEBP, Bertolucci SKV, Rossi ZTT, Lima AF, Silva ST \& Silva GM (2015) Micropropagação e germinação de sementes in vitro de atroveran. Revista Ceres 62: 215-223.

Moraes CP, Souza-Leal T, Panosso AR \& Souza MC (2012) Efeitos da escarificação química e da concentração de nitrogênio sobre a germinação e o desenvolvimento in vitro de Vanilla planifolia Jack ex Andr. (Orchidaceae: Vanilloideae). Acta Botanica Brasilica 26: 714-719.

Nobel PS (2002) Cacti: biology and uses. University of California, Berkeley. 280p.

Nunes EN, Lemos DM, Silva SF, Rocha APT, Lucena CM, Meiado MV \& Lucena RFP (2016) Quantification physicochemical in melon cactus (Melocactus zehntneri (Britton \& Rose) Luetzelburg - Cactaceae). Revista Brasileira de Plantas Medicinais 18: 81-88.

O'Brien TP, Feder N \& McCully ME (1964) Polyehromatic staining of plant cell walls by toluidine blue O. Protoplasma 59: 368-373.

Quiala E, Matos J, Montalvo G, Feria M, Chávez M, Capote A, Pérez N, Barbón R \& Kowalski B (2009) In vitro propagation of Pilosocereus robinii (Lemaire) Byles et Rowley, endemic and endangered cactus. Journal of the Professional Association for Cactus Development 11:18-25.

Rojas-Aréchiga M \& Vázquez-Yanes C (2000) Cactus seed germination: a review. Journal of Arid Environments 44: 85-104.

Secorun AC \& Souza LA (2011) Morphology and anatomy of Rhipsalis cereuscula, Rhipsalis floccosa 
subsp. hohenauensis and Lepismium cruciforme (Cactaceae) seedlings. Revista Mexicana de Biodiversidad 82: 131-143.

Souza LA (2003) Morfologia e anatomia vegetal: célula, tecidos, órgãos e plântula. Editora Todapalavra, Ponta Grossa. 258p.

Terrazas T \& Arias S (2003) Comparative stem anatomy in the subfamily Cactoideae. The Botanical Review 68: 444-473.

Zaidan LBP \& Barbedo CJ (2004) Quebra de dormência em sementes. In: Ferreira AG \& Borghetti F (eds.) Germinação: do básico ao aplicado. Artmed, Porto Alegre. 322p.
Zappi D, Taylor N, Ribeiro-Silva S, Machado M, Moraes EM, Calvente A, Cruz B, Correia D, Larocca J, Assis JG, Aona L, Menezes MOT, Meiado M, Marchi MN, Santos MR, Bellintani M, Coelho P, Nahoum PI \& Resende S (2011) Plano de ação nacional para a conservação das Cactáceas. Instituto Chico Mendes de Conservação da Biodiversidade, Brasília. 112p.

Zobayed SMA, Afreen-Zobayed F, Kubota C \& Kozai T (2000) Mass propagation of Eucalyptus camaldulensis in a scaled-up vessel under in vitro photoautotrophic condition. Annals of Botany 85: 587-592. 